\title{
Distinct prognostic values of programmed death-ligand 1 and programmed cell death protein 1 in lung adenocarcinoma and squamous cell carcinoma patients
}

\author{
Shuo Wang ${ }^{1,2,3}$, Xiujuan $\mathrm{Qu}^{1,2,3}$, Zhi Li ${ }^{1,2,3}$, Xiaofang Che ${ }^{1,2,3}$, Lili Cao ${ }^{1,2,3}$, Xianghong Yang ${ }^{4}$, Xuejun $\mathrm{Hu}^{5}$, \\ Ling Xu ${ }^{1,2,3}$, Kezuo Hou ${ }^{1,2,3}$, Yibo Fan ${ }^{1,2,3}$, Ti Wen ${ }^{1,2,3}$, Yunpeng Liu ${ }^{1,2,3}$ \\ ${ }^{1}$ Department of Medical Oncology, the First Hospital of China Medical University, Shenyang, China; ${ }^{2}$ Key Laboratory of Anticancer Drugs and \\ Biotherapy of Liaoning Province, the First Hospital of China Medical University, Shenyang, China; ${ }^{3}$ Liaoning Province Clinical Research Center \\ for Cancer, Shenyang, China; ${ }^{4}$ Department of Pathology, Shengjing Hospital of China Medical University, Shenyang, China; ${ }^{5}$ Department of \\ Respiratory Medicine, the First Hospital of China Medical University, Shenyang, China \\ Contributions: (I) Conception and design: Y Liu, X Qu; (II) Administrative support: Y Liu, X Qu; (III) Provision of study materials or patients: \\ S Wang; (IV) Collection and assembly of data: S Wang, X Che, L Cao, X Yang, X Hu, L Xu, K Hou, Y Fan, T Wen; (V) Data analysis and \\ interpretation: S Wang, Z Li; (VI) Manuscript writing: All authors; (VII) Final approval of manuscript: All authors. \\ Correspondence to: Yunpeng Liu; Xiujuan Qu. Department of Medical Oncology, Key Laboratory of Anticancer Drugs and Biotherapy of \\ Liaoning Province, the First Hospital of China Medical University, No. 155, North Nanjing Street, Heping District, Shenyang 110001, China. \\ Email: cmuliuyunpeng@hotmail.com; xiujuanqu@yahoo.com.
}

\begin{abstract}
Background: Although immunotherapy has demonstrated similar clinical activities in the treatment of lung adenocarcinoma (ADC) and squamous cell carcinoma (SCC), several studies have shown programmed deathligand 1 (PD-L1) to have different predictive roles in ADC and SCC. This study was conducted to compare the different functions of PD-L1/programmed cell death protein 1 (PD-1) pathway in these malignancies.

Methods: A multi-dimensional analysis based on public databases and 2 independent cohorts including 262 patients with lung cancer was performed. Immunohistochemistry (IHC) and fluorescence-based multiplexed staining were used to detect the immune factors.

Results: PD-L1 was observed to have different expressions and regulatory mechanisms between SCC and ADC. PD-L1 was significantly increased from the messenger RNA (mRNA) to protein levels in the SCC group compared with the ADC group. Also, PD-L1 on tumor cells (TCs) was positively correlated with $\mathrm{CD}^{+}$tumor lymphocyte infiltrates in ADC, but not in SCC. More importantly, PD-L1 was considered to be an independent predictor of overall survival (OS) for ADC patients. In contrast, in SCC patients, PD- $1^{+}$ tumor-infiltrating lymphocytes (TILs) were considered a poor prognostic predictor.

Conclusions: These findings showed that PD-L1 in ADC and PD- $1^{+}$TILs in SCC respectively indicates T-cell function, which plays a crucial role in determining prognosis. The distinct functions of the biomarkers between ADC and SCC might provide potential avenues for guiding anti-PD-1/PD-L1 immunotherapy.
\end{abstract}

Keywords: Prognostic values; PD-L1; PD-1; lung adenocarcinoma; squamous cell carcinoma

Submitted Jan 21, 2020. Accepted for publication Dec 01, 2020.

doi: 10.21037/atm-20-968

View this article at: http://dx.doi.org/10.21037/atm-20-968

\section{Introduction}

The checkpoint inhibitors that target the programmed cell death protein 1 (PD-1)/programmed death-ligand 1 (PD-
L1) pathway represent a significant breakthrough in the treatment of non-small cell lung cancer (NSCLC) (1-5). However, only $15-20 \%$ of patients who receive PD-1/ PD-L1 inhibitor therapy show a clinical response without 
screening. Therefore, elucidating the factors that could determine which patients would benefit from this treatment has become a primary priority.

The expression of PD-L1 has been extensively investigated as a predictive biomarker in human cancer. Most previous studies have found a high expression of PD-L1 correlated with an improved response rate $(2,3)$; however, clinical response has also been observed in $\mathrm{PD}$ L1 negative patients (6) the response in PD-L1-positive patients is unsatisfactory. Multiple factors can explain this limitation; firstly, a uniform assay is lacking for the assessment of PD-L1 (2-7); secondly, the immune tumor microenvironment (TME) is complex, with functional interrelation of several factors $(8,9)$; and finally, tumor heterogeneity might lead to differential expression of PD$\mathrm{L} 1$ between different tumors in the same patient $(7,10,11)$.

The status of immunosuppression is also considered to be related to tumor development in patients. Immune factors such as PD-L1 and PD-1 may serve as prognostic biomarkers indicating the patient's survival, independent of the immune checkpoint inhibitors received. Therefore, we set out to investigate the prognosis that is unrelated to treatment and reflects the tumor's intrinsic factors.

Specifically, the two clinical trials of OPDIVO ${ }^{\circledR}$ (nivolumab) in previously treated NSCLC patients, CheckMate 017 for squamous cell carcinoma (SCC) and CheckMate 057 for non-squamous (non-SCC) NSCLC, showed similar clinical improvement in the overall survival (OS) rate; however, the predictive role of PD-L1 was variable $(1,2)$. No association was found between PD-L1 expression and SCC response, but a significant association was observed in non-SCC NSCLC. These findings indicated that the expression and biological significance of the PD-L1/ PD-1 pathway might differ between these two cancer types. However, most of the studies to date have analyzed PDL1 and PD-1 in the total population of NSCLC patients, ignoring the potential effects of their divergence. This could partly explain the inconsistent results of studies on their prognostic roles in NSCLC (11-17). Therefore, it is necessary to assess the PD-L1/PD-1 pathway differences in different pathological types of NSCLC.

Hence, in the current study, an integrated analysis that incorporated results from a public database and two independent NSCLC patients' independent cohorts was undertaken. PD-L1 and PD-1 expression, and CD $8^{+}$ T-cell infiltration were detected by immunohistochemistry (IHC) and multiplexed IHC staining (mIHC), and their prognostic values in lung adenocarcinoma (ADC) and SCC were analyzed, respectively. From the results, we found distinct prognostic biomarkers that potentially reflect $T$ cell function in NSCLC subgroups. We present the following article following the REporting recommendations for tumor MARKer (REMARK) reporting checklist (available at http://dx.doi.org/10.21037/atm-20-968).

\section{Methods}

\section{Study population}

This study was conducted on two independent cohorts of NSCLC patients from Shengjing Hospital of China Medical University (cohort 1) and the First Hospital of China Medical University (cohort 2). Samples of NSCLC tissue from the archive of the institute of Pathology were reviewed. Clinical data including sex, age at diagnosis, smoking status, tumor differentiation, and epidermal growth factor receptor (EGFR) mutation status were collected from patient medical records, and pathological tumor node metastasis (TNM) stage was defined by the American Joint Committee on Cancer (AJCC) 7th edition. The inclusion criteria were: $<75$ years old; primary NSCLC with stage I-III; R0 resection; pathological type classified as SCC or ADC; and treatment-naive before surgery. The patients received standard therapy after surgery, either platinumbased adjuvant chemotherapy or observation, according to their TNM stage and the National Comprehensive Cancer Network (NCCN) guidelines.

The Shengjing Hospital cohort comprised retrospectively collected formalin-fixed paraffin-embedded (FFPE) samples from 118 lung carcinomas between January 2010 and December 2010, with an average follow-up of 56 months (range, 3-66 months). The First Hospital cohort consisted of 144 lung carcinomas between 2012 and 2014, with an average follow-up of 55 months (range, 7-75 months). A detailed description of the baseline characteristics of the two cohorts is displayed in Table S1. The study was conducted in line with the Declaration of Helsinki (as revised in 2013) and approved by the Ethics Committee at the First Hospital of China Medical University (AF-SOP-07-1.1-01). All patients signed informed consent form.

\section{IHC}

Tissue samples were prepared and preserved in FFPE. Serial $4-\mu m$-thick sections were prepared through deparaffination in xylene and dehydration with graded alcohols. For 
IHC staining, the procedure was performed followed by the standard procedure for the UltraSensitiveTM SP (Mouse/Rabbit) IHC Kit (\#9710, Maixin Biotech, Fuzhou, Fujian, China). Firstly, heat-induced antigen retrieval in citrate buffer was conducted. After blocking with bovine serum albumin (BSA), the sections were incubated with the following primary antibodies at $4{ }^{\circ} \mathrm{C}$ overnight: PDL1 (\#13684, clone E1L3N, CST), CD8 (MAB-0021, clone c8/144B, Maixin Biotech, Fuzhou, Fujian, China), PD-1 (\#86163, clone D4W2J, CST). Next, the sections were treated with second antibody-peroxidase-linked polymers and visualized with 3,3-diamino-benzidine tetrahydrochloride (DAB; Maixin Biotech, China).

\section{Evaluation of IHC}

All specimens were examined independently by two experienced pathologists who were blinded to all clinical outcomes. In cases of disagreement between the two pathologists, a third pathologist was consulted to achieve consensus. Tumor cells (TCs) and tumorinfiltrating immune cells (TIICs) were scored separately. PD-L1 positivity in TCs was defined as $\geq 5 \%$ TCs having membrane staining. For immune cells (ICs), positivity was defined as $\geq 1 \%$ of the TIICs in the tumor area being PDL1 positive (5). Either TC or IC positivity was considered as $\mathrm{PD}-\mathrm{L} 1$ positive. $\mathrm{PD}-1$ in tumor-infiltrating lymphocytes (TILs) was assessed by counting the percentage of PD-1positive TILs; PD-1 positivity was counted as $\geq 1 \%$ of the TILs being PD-1 positive. The value of CD8 was evaluated on the extent of positive lymphocytes infiltrating within TCs. Staining of CD8 cells was defined as less or more if the tumor site's median value was $<20 \%$ or $\geq 20 \%$.

\section{Multiplexed IHC staining (mIHC)}

mIHC was performed using the OpalTM7-Color Manual IHC Kit (PerkinElmer Inc., Waltham, MA, USA) according to the manufacturer's instructions. The primary antibodies used were the same as those used for IHC staining. Briefly, antigen retrieval was carried out in ethylene-diamine-tetraacetic acid (EDTA) buffer (pH 9.0) using microwave incubation (MWT) for $10 \mathrm{~min}$. After cooling down, slides were covered with blocking buffer and incubated in a humidified chamber for $10 \mathrm{~min}$ at room temperature. Primary antibodies for CD8 were incubated for $1 \mathrm{~h}$ at room temperature followed by detection using the Opal Polymer HRP Ms+Rb (PerkinElmer Inc., Waltham, MA, USA) for $10 \mathrm{~min}$.
Opal signal generation of CD8 was accomplished using Opal 690 TSA Plus for $10 \mathrm{~min}$, after which the slides were placed in EDTA buffer and heated using MWT to remove primary and secondary antibodies. Serially, we staining for PD-1, PD-L1, and pan-CK (MAB-0671, and clone MX005, Maixin Biotech, Fuzhou, Fujian, China) was performed. Nuclei were subsequently stained with 4',6-diamidino-2-phenylindole (DAPI) for $5 \mathrm{~min}$, and the sections were coverslipped with Vectashield HardSet mounting media (Vector Laboratories Inc., Burlingame, CA, USA).

\section{Imaging and analysis}

The slides were scanned using the Mantra System (PerkinElmer, Waltham, MA, USA). To establish the spectral library required for multispectral unmixing, images of unstained tissue and single-stained tissues were used to extract the autofluorescence spectrums of tissue and each fluorophore. The machine-learning platform InForm (PerkinElmer, Waltham, MA, USA) was used for tissue segmentation, cell segmentation, and intensity measurements. The marker creatine kinase (CK) was used to identify TCs; PD-1 and CD8 were used to detect TILs. Different cell types were quantified as a proportion to all cells. The levels of IC PD-L1, PD-1, and CD8 were classified as positive/negative using the median as the cutoff. Positivity of TC PDL- 1 was defined as $\geq 1 \%$.

\section{Messenger RNA (mRNA) expression profiling and Gene Ontology (GO) analysis}

For The Cancer Genome Atlas (TCGA) datasets, the RNA sequencing (RNA-Seq) (level 2) data of 594 adenocarcinomas and 551 SCCs were downloaded from the TCGA website and preprocessed according to the Bioconductor/ TCGAbiolinks package. Genes co-expressed with PD-L1 in TCGA were selected for GO analysis by the Database for Annotation, Visualization and Integrated Discovery (DAVID, https://david.ncifcrf.gov). Seven Gene Expression Omnibus (GEO) datasets were enrolled for meta-analysis; four datasets (GSE37745, GSE30219, GSE8894, and GSE19188) that consisted of ADC and SCC groups were selected for comparative analysis. The cut-off values were chosen as the median of the entire dataset.

\section{Statistical analysis}

Analyses were performed using SPSS version 16.0 (IBM 
Corp., Armonk, NY, USA) and R software 3.0.2 (R Foundation for Statistical Computing, Vienna, Austria, https://www.R-project.org/). Associations between clinicopathological parameters and PD-L1/PD-1 expression were assessed with the chi-squared (2) or Fisher's exact test, as appropriate. Spearman's correlation coefficients were obtained to explore the relationships between PDL1 and CD8 expression. Welch's two-sample $t$-test was used to compute the $\mathrm{P}$ value for continuous variables. Kaplan-Meier analysis and log-rank tests were used for survival analysis. To evaluate the prognostic value of $\mathrm{PD}$ L1 and PD-1, univariate and multivariate analyses using a Cox proportional hazard regression classification were carried out, and hazard ratios (HRs) were estimated with $95 \%$ confidence interval (CI) limits. A $\mathrm{P}$ value $<0.05$ was considered statistically significant.

A meta-analysis based on the SurvExpress database was carried out. The study names, sample size, HR, and 95\% CI were extracted. The pooled HR with a 95\% CI was obtained by calculating the weighted average of the individual $\log (\mathrm{HR})$ estimates. A pooled HR $>1$ implied a worse survival for the group with high expression. Data were considered statistically significant if the $95 \%$ CI for the combined HR did not overlap.

\section{Results}

\section{Patient characteristics}

Cohort 1 comprised 70 ADC and 48 SCC patients, with a median age of 59 years (range, 30-75 years). At the final follow-up (June, 2015), 55 (46.7\%) patients had relapsed and $47(39.8 \%)$ patients had died due to the disease. Cohort 2 included 98 ADC and 46 SCC patients, with a median age of 59 years (range, 34-75 years). At the final followup (June, 2018), 71 (49.3\%) patients had relapsed and $41(28.5 \%)$ patients had died due to the disease. Information on the smoking status, histological type, TNM stage, tumor differentiation, and EGFR mutation status of ADC and SCC patients in the two independent cohorts is summarized in Table S1. There were no significant differences between the two cohorts in terms of baseline characteristics.

\section{The expression levels of PD-L1 and PD-1 mRNA}

First, the expression levels of PD-L1 mRNA were compared between ADC and SCC. The GEO datasets showed that the PD-L1 mRNA levels in the SCC group were increased compared to those in the ADC group (Figure S1A,B,C), except for GSE19188, in which statistical significance was not achieved (Figure S1D). In contrast with PD-L1, little difference was observed in PD-1 mRNA levels between the SCC and ADC subtypes in the GEO datasets (Figure S1E,F,G,H).

\section{PD-L1 expression was increased in the SCC group compared to the $A D C$ group}

Next, IHC staining was used to investigate PD-L1 protein expression in cohort 1. Typically, the staining of PD-L1 is membrane-accentuated, which was often accompanied by low-intensity cytoplasmic staining. A total of $41 / 118$ patients $(34.7 \%)$ showed PD-L1 positivity in TCs, and $71 / 118$ patients $(60.2 \%)$ in ICs. PD-L1 was expressed more frequently in the SCC sub-type (Figure $1 A, B, C$ ) than in the ADC sub-type (Figure 1D,E,F) (TCs: $54.2 \%$ in SCC vs. 21.4\% in ADC; ICs: $85.4 \%$ in SCC vs. $42.9 \%$ in $\mathrm{ADC}, \mathrm{P}<0.05$ ).

For PD-1 expression, most PD- $1^{\text {pos }}$ cells were distributed in the stromal bands dissecting the tumor mass or within tumor-infiltrating IC small aggregates, whereas others were expressed on TCs. In cohort 1, 45/118 patients (38.1\%) were defined as IC PD- $1^{\text {pos }}$, and no significant difference was found in positivity between the two subtypes (39.6\% in SCC vs. $37.1 \%$ in $\mathrm{ADC}, \mathrm{P}>0.05$ ) (Figure $1 G, H, I, \mathcal{7}, K, L$ ).

\section{Expression of PD-L1 and PD-1 by $\mathrm{mIHC}$}

The assessment of immune markers by IHC was semiquantitative and relatively crude. Therefore, to quantify and localize ICs in a more detailed manner, multiplexed immunofluorescence staining was conducted in cohort 2 . Consistent with the IHC results, PD-L1 expression was more commonly observed in ICs than in TCs (IC median $3.52 \%, 0.02-86.76 \%$ vs. TC median $0.5 \%, 0-35.36 \%$ ) (Figure $2 A$ ). In total, $52 / 144$ patients $(36.1 \%)$ were found to be TC PD-L1 ${ }^{\text {pos }}$ (30.6\% in ADC vs. $47.8 \%$ in SCC, $\mathrm{P}<0.05)$. Using the median as the cut-off value, $43.9 \%$ and $63.0 \%$ of patients in the ADC and SCC groups, respectively, were defined as IC PD-L1 ${ }^{\text {pos }}$.

In cohort 2, the distribution of PD-1 was similar, but not completely coincident, to that of $\mathrm{CD} 8$, indicating that PD-1 was not limited to T cells (Figure 2B). The positivity of PD-1 in ADC and SCC was $49.0 \%$ and $45.7 \%$, 

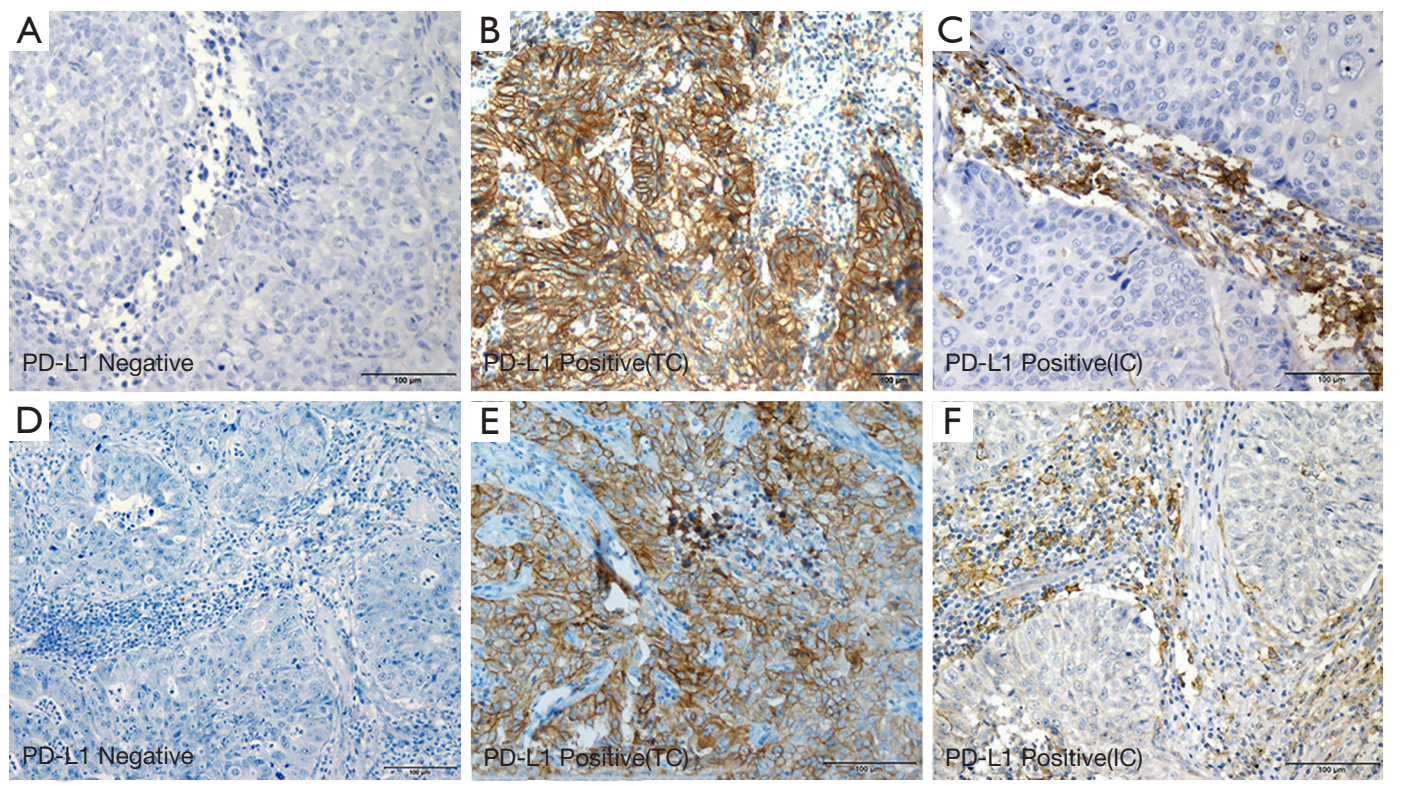

$\operatorname{SCC}$
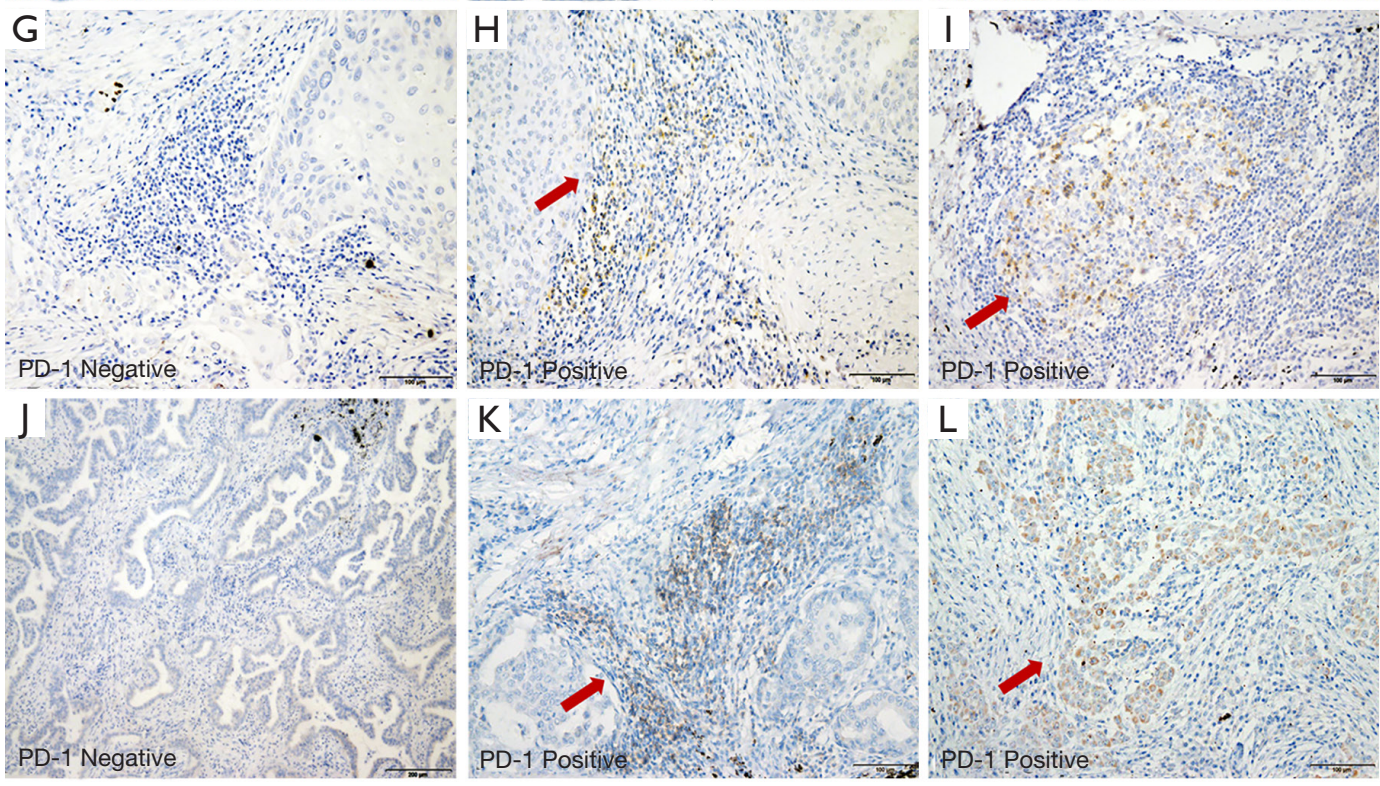

$\operatorname{scC}$

$\mathrm{ADC}$

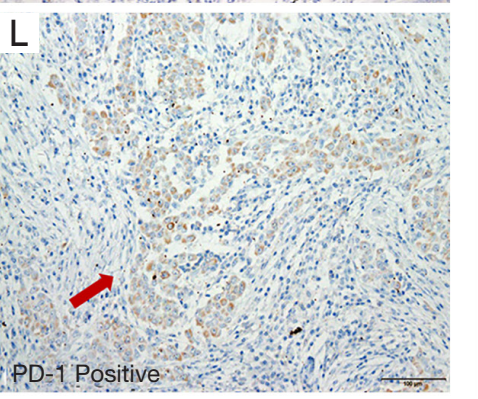

$\mathrm{ADC}$

Figure 1 Expression of PD-L1 and PD-1 detected by IHC. Representative images of PD-L1 and PD-1 staining in NSCLC samples are shown at 200× $(100 \mu \mathrm{m})$ magnification. Negative expression of PD-L1 in SCC (A) and ADC (D). Positive expression of TC PD-L1 in SCC (B) and ADC (E). Positive expression of IC PD-L1 in SCC (C) and ADC (F). Negative expression of PD-1 in SCC (G) and ADC (J). Positive expression of PD-1 in TILs in SCC (H) and ADC (K). Positive expression of PD-1 in areas of lymphocyte aggregates (I) and tumor cells (L). SCC, squamous cell carcinoma; ADC, lung adenocarcinoma; TC, tumor cell; IC, immune cell; TILs, tumor infiltrating lymphocytes; IHC, immunohistochemistry; NSCLC, non-small cell lung carcinoma. The arrows indicated positive expression.

respectively.

\section{Expression of $C D 8^{+}$T lymphocytes}

For further assessment, genes co-existing with PD-L1 in
TCGA were predicted. A total of 60 genes in ADC and 2 genes (PD-L1 and PD-1) in SCC were selected with a Pearson correlation coefficient of $\geq 0.4$. These genes were annotated in the GO analysis, and the results indicated that the genes co-expressed with PD-L1 in ADC mostly 
A
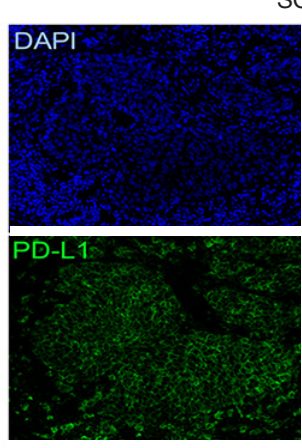

B


SCC
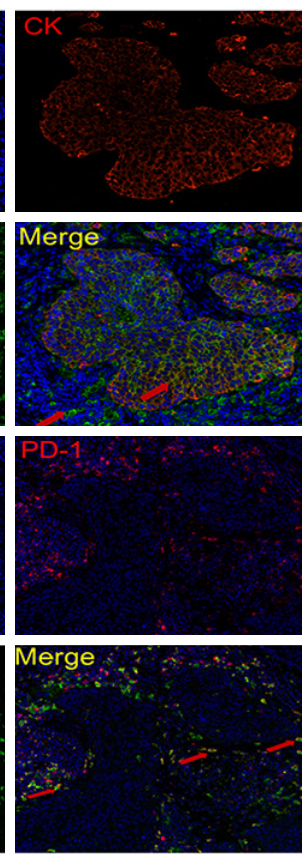
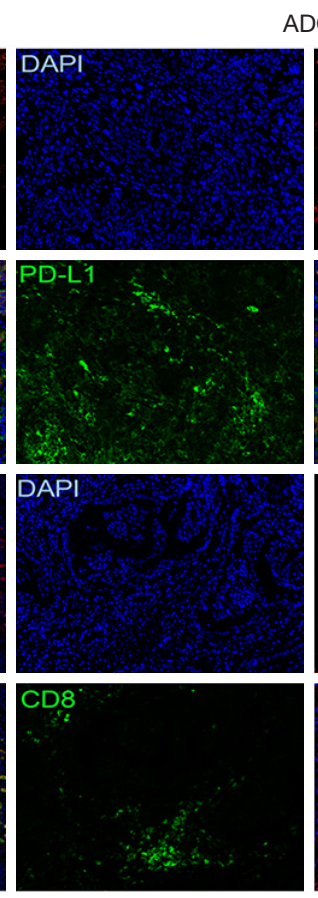

$\mathrm{ADC}$
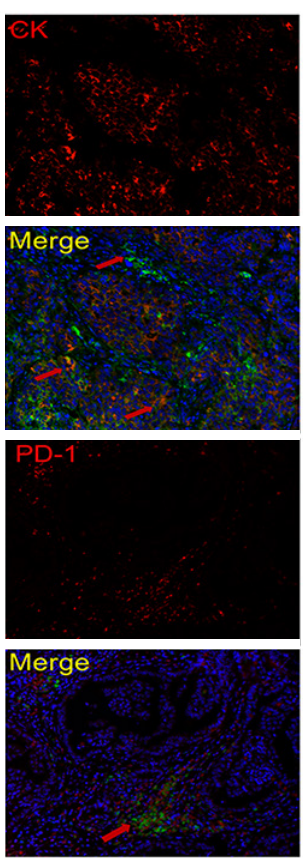

Figure 2 Expression of PD-L1 and PD-1 detected by multiplexed immunofluorescence Images are shown at 200× (100 $\mu \mathrm{m})$ magnification. (A) Representative images of the immunofluorescence staining with DAPI (blue), cytokeratin (red), and PD-L1 (green) on NSCLC tissues. PDL1 was expressed on tumor cells and in the peritumoral stroma in SCC and ADC. The arrows indicted positive expression both of PD-L1 and CK. (B) Representative images of the immunofluorescence staining with DAPI (blue), PD-1 (red), and CD8 (green) on NSCLC tissues. PD-1 was expressed mainly in the peritumoral stroma in SCC and ADC. The arrows indicted positive expression both of PD-1 and CD8. DAPI, 4',6-diamidino-2-phenylindole; NSCLC, non-small cell lung carcinoma; SCC, squamous cell carcinoma; ADC, adenocarcinoma.

participated in immune response (Table S2). Nevertheless, as there were too few genes to evaluate, further analysis was impossible in SCC.

As $\mathrm{CD}^{+} \mathrm{T}$ cells play a central role in immune response, $\mathrm{CD}^{+} \mathrm{T}$ cells' expressions were assessed first. Conventional IHC staining showed $\mathrm{CD} 8^{+} \mathrm{T}$ cells to have a diffuse pattern, with more cells in the peritumoral areas than within the tumor nests (Figure $3 A$ ). Using $20 \%$ as the cut-off value, almost half of the patients $(53 / 118,44.9 \%)$ had more CD $8^{+} \mathrm{T}$ cell infiltration. The SCC group demonstrated significantly higher $\mathrm{CD}^{+} \mathrm{T}$ cells levels compared to the ADC group (58.3\% in SCC vs. $35.7 \%$ in ADC, $\mathrm{P}<0.05$ ). According to $\mathrm{mIHC}$ staining, three patterns of $\mathrm{T}$ cells associated with TCs were demonstrated: (I) CD8 ${ }^{+}$TILs infiltrating the peritumoral and tumor areas simultaneously (Figure 3B); (II) CD8 ${ }^{+}$TILs limited to the peritumoral areas, with little infiltration of tumor areas (Figure 3C); and (III) very low T-cell infiltration (data not shown).

\section{Different relationships between $P D-L 1$ and $C D 8^{+} T$ lymphocytes}

Next, the correlations of $\mathrm{CD} 8^{+} \mathrm{T}$ cells with PD-L1 were examined in the subgroups. Increasing density of $\mathrm{CD}^{+}$TILs showed a positive correlation with IC PD-L1 in both the $\mathrm{ADC}$ and SCC groups. In the ADC group, $\mathrm{CD} 8^{+} \mathrm{TILs}$ were positively correlated with TC PD-L1; however, no significant relationship was observed in the SCC group (Table S3). These results suggested that the mechanisms in the upregulation of PD-L1 were potentially different between ICs and TCs, and especially between ADC and SCC.

\section{$P D-L 1$ was the survival predictor for ADC patients}

A meta-analysis of TCGA and GEO databases was carried out to evaluate the prognostic value of PD-L1. There were 7 studies including 1,115 ADC participants and 
A
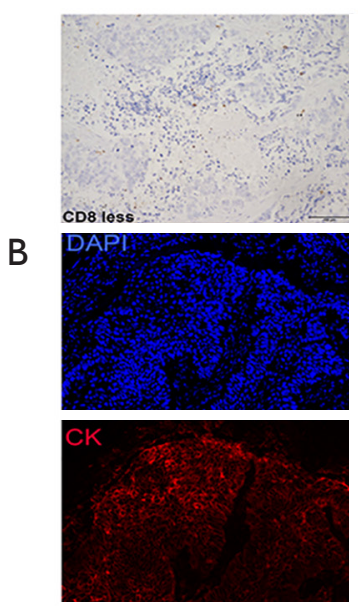

C
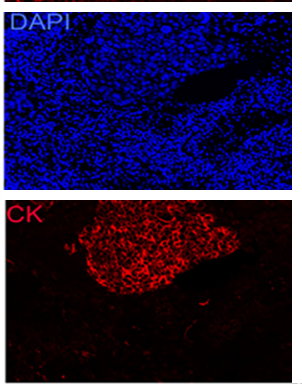

SCC
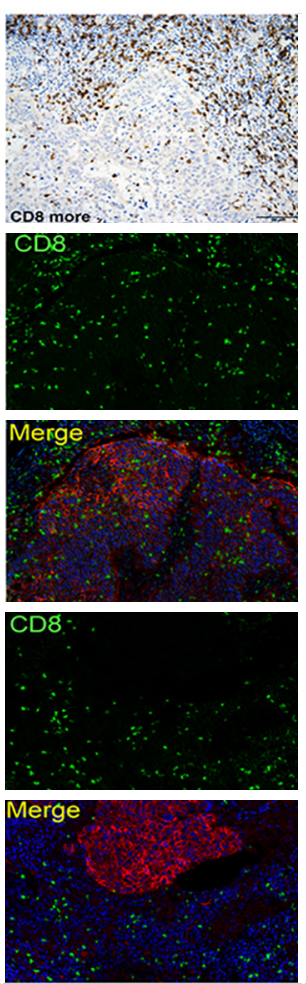

ADC
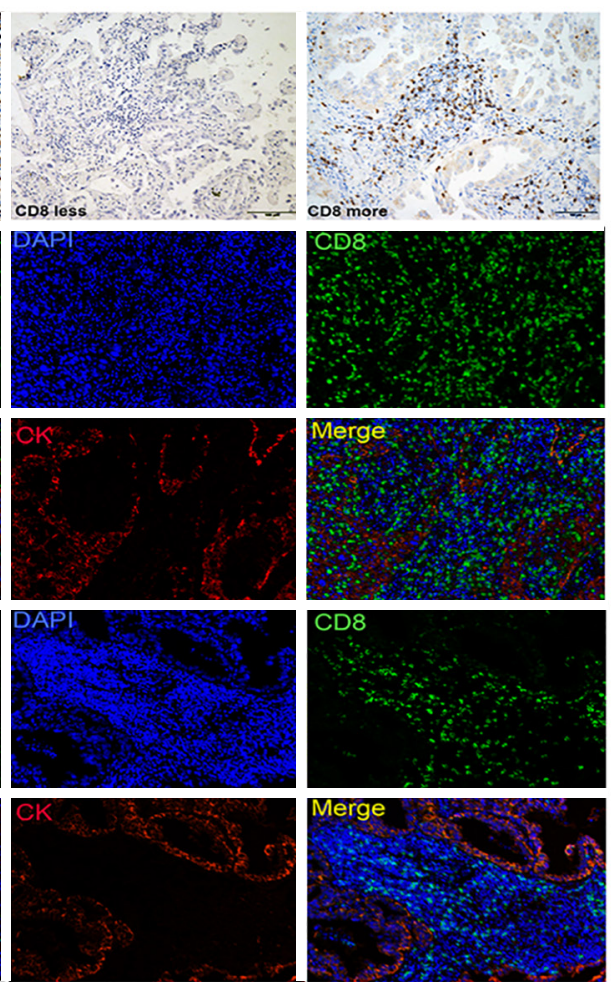

Figure 3 Expression of CD8. Images are shown at 200× (100 $\mu \mathrm{m})$ magnification. (A) Representative images of negative and positive CD8 expression in SCC and ADC tissue detected by IHC. Representative images of the immunofluorescence staining with DAPI (blue), cytokeratin (red), and CD8 (green) on NSCLC tissues. (B) CD8 was expressed in peri-tumoral areas with infiltration into tumor tissue. (C) CD8 was expressed in peri-tumoral areas with less infiltration into tumor tissue. SCC, squamous cell carcinoma; ADC, adenocarcinoma; IHC, immunohistochemistry; DAPI, 4',6-diamidino-2-phenylindole; NSCLC, non-small cell lung carcinoma.

8 studies including 656 SCC enrolled participants. The main characteristics of these studies are summarized in Table S4. As the heterogeneity test showed no significant differences $\left(\mathrm{I}^{2}=18.6 \%\right.$ and 0 in $\mathrm{ADC}$ and SCC, $\mathrm{P}=0.2883$ and 0.9101 , respectively), a fixed-effects model was used. The results showed that high PD-L1 mRNA levels were strongly correlated with shorter OS in ADC population (pooled HR $=1.27,95 \%$ CI, 1.01-1.58, Figure S2A). However, the $95 \%$ CI was overlapped for the SCC population, indicating no such correlation (Figure S2B).

To confirm these observations from public databases, the relationship of PD-L1 expression with OS and diseasefree survival (DFS) were evaluated in the two cohorts. In Kaplan-Meier analysis, ADC patients with PD-L1 ${ }^{+}$TCs (Figure $4 A, B, C, D$ ) or ICs (Figure 4E,F,G,H) had worse OS and DFS than patients with PD-L1- TCs or ICs. In the SCC population, PD-L1 expression showed no significant prognostic value for OS or DFS (Figure 4I, F, K,L, M,N,O,P).

\section{PD-1+ TIL predicted survival for SCC patients}

Next, the TCGA and GEO databases were meta-analyzed again, as previously described. PD-1 mRNA level was not found to be correlated with OS in either the ADC (Figure S2C) or the SCC (Figure S2D) population. PD- $1^{+}$TILs, as assessed by IHC in cohort 1 , were not associated with OS or DFS in ADC patients (Figure 5A,B); however, PD- $1^{+}$TILs were associated with worse OS and DFS in SCC patients (Figure $5 C, D$ ). In cohort 2 , the overall count of $\mathrm{PD}-1^{+}$cells in the stroma was again observed to have no prognostic value in either group (Figure $5 E, F, G, H$ ). This result was similar to that arising from online data analysis. Since we found in cohort 1 that PD- $1^{+}$TILs had a prognostic effect, we then investigated whether the combination of PD-1 stroma expression and $\mathrm{CD} 8^{+} \mathrm{T}$ cells could identify subgroups of patients with a distinct prognosis in cohort 2 . As expected, a low $\mathrm{CD}^{+} \mathrm{PD}-1^{+} \mathrm{T}$-cell count was related to 
Table 1 Univariate and multivariate survival analysis in Cohort No. 1

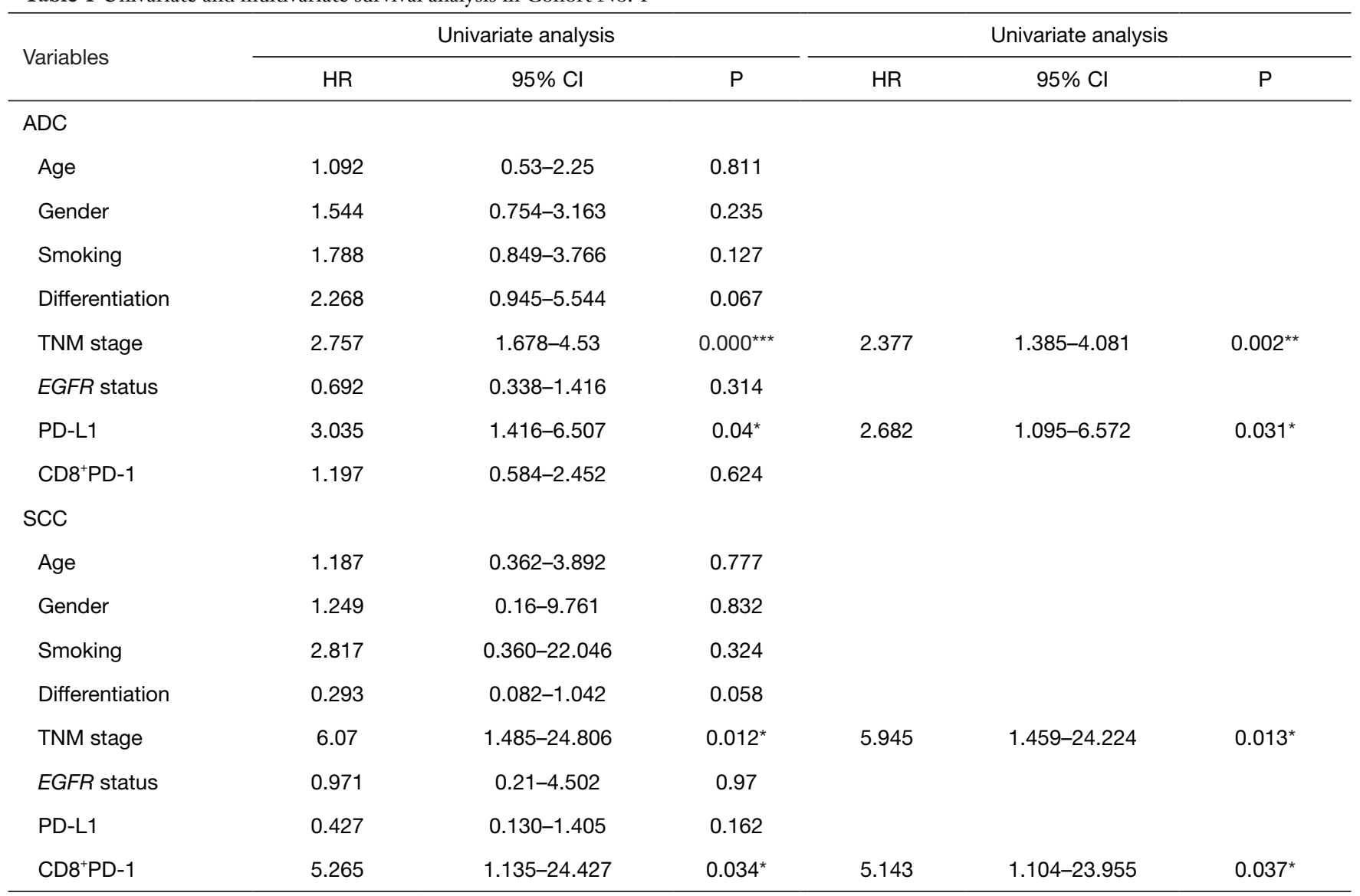

*, $\mathrm{P}<0.05 ;{ }^{* *}, \mathrm{P}<0.01 ;{ }^{* \star *}, \mathrm{P}<0.001$.

superior survival only in the SCC subgroup ( $\mathrm{P}=0.018$ for OS and $\mathrm{P}=0.01$ for DFS) (Figure $5 I, \mathcal{7}, K, L$ ).

\section{Univariate and multivariate analyses of independent prognostic factors}

In univariate analysis, PD-L1 expression (either TC or IC), tumor differentiation, and pTNM stage were associated with OS in ADC patients and were then selected for multivariate analyses. For SCC patients, pTNM stage, PD- $1^{+}$TILs, or CD8 ${ }^{+}$PD-1 showed associations with OS (in cohort 1, tumor differentiation was also selected for multivariate analyses with $\mathrm{P}=0.058$ ) (Table 1 and Table S5). Finally, multivariate analysis of the ADC sub-group showed that PD-L1 expression was an independent predictor of OS $(\mathrm{HR}=2.682, \mathrm{P}=0.031$ in cohort $1 ; \mathrm{HR}=2.658, \mathrm{P}=0.028$ in cohort 2) as was TNM stage ( $\mathrm{HR}=2.377, \mathrm{P}=0.002$ in cohort 1 ; $\mathrm{HR}=2.507, \mathrm{P}<0.001$ in cohort 2). Meanwhile, in the SCC sub-group, PD- $1^{+}$TILs (HR $=5.143, \mathrm{P}=0.037$ in cohort $1, \mathrm{HR}=2.304, \mathrm{P}=0.053$ in cohort 2 ) and TNM stage $(\mathrm{HR}=5.945, \mathrm{P}=0.013$ in cohort $1 ; \mathrm{HR}=2.482, \mathrm{P}=0.003$ in cohort 2) were considered to be independent predictors of poorer OS.

\section{Discussion}

This study was driven by the question of whether or not PD-L1 expression exhibited different predictive values in ADC and SCC in clinical trials; thus, we explored the differences in expression and function of PD-L1/PD-1 in $\mathrm{ADC}$ and SCC through an extensive analysis. Interestingly, we found that PD-L1/PD-1 up-regulation mechanisms and their prognostic values differed between the two subtypes. As the current checkpoint blockade therapies mainly focus on sustaining $\mathrm{T}$ cells against exhaustion, $\mathrm{T}$ cells' function was considered a critical predictor for both prognosis and 
Cohort No.1

A

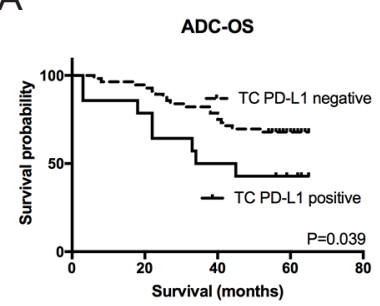

E

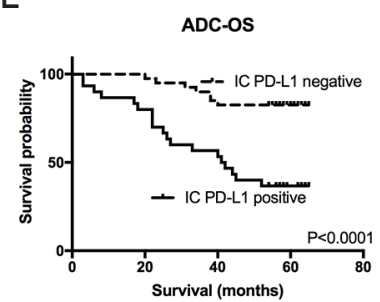

I

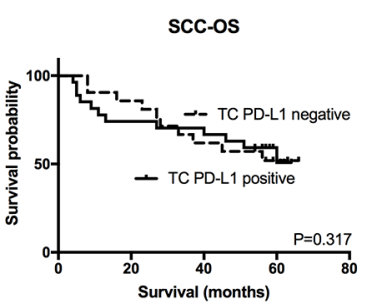

M

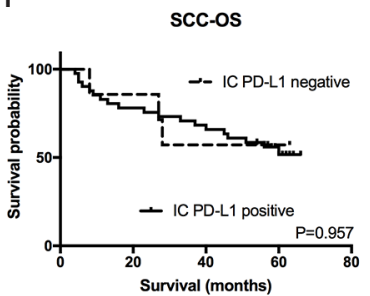

B

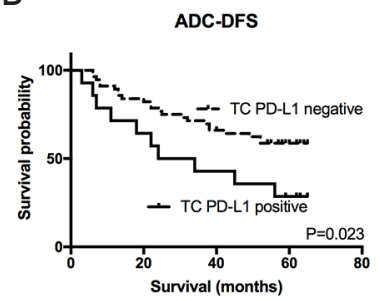

$\mathrm{F}$

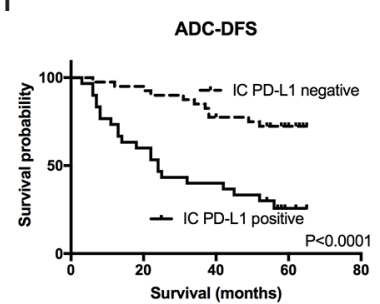

J

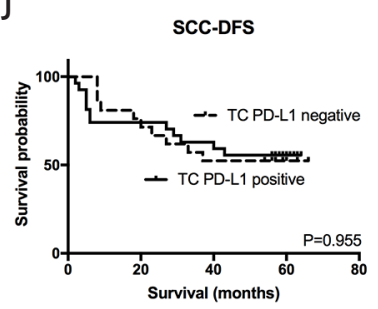

$\mathrm{N}$

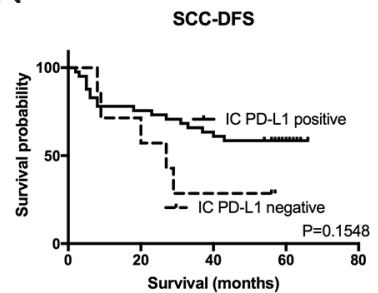

Cohort No.2

C

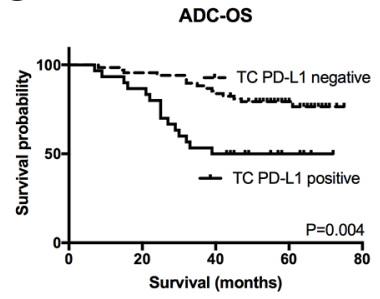

G

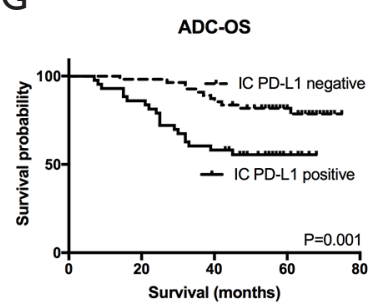

K

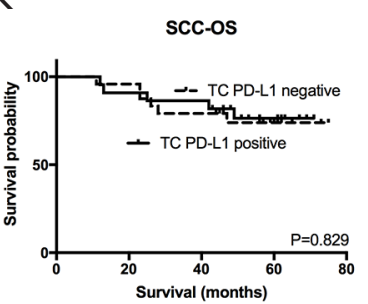

O

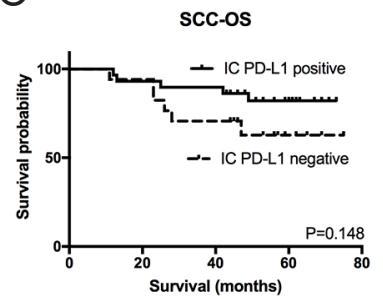

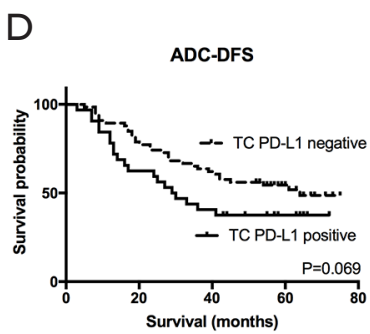

$\mathrm{H}$

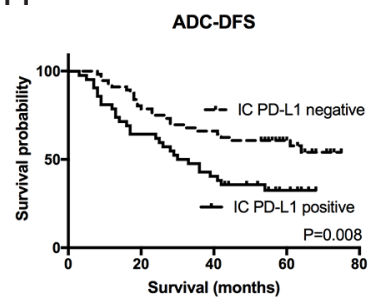

$\mathrm{L}$

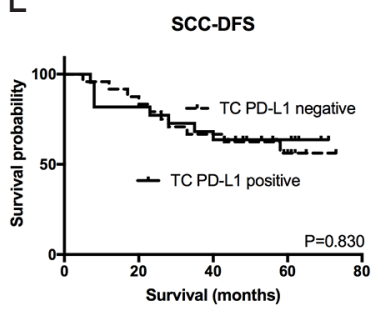

P

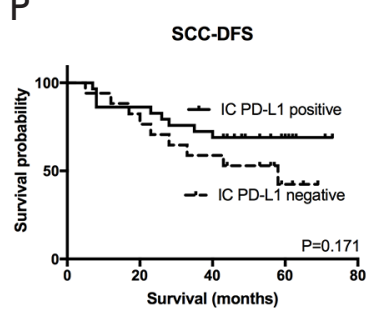

Figure 4 Kaplan-Meier survival analysis for PD-L1 expression. ADC patients with positive TC PD-L1 (A,B,C,D), IC PD-L1 (E,F,G,H) exhibited a significantly worse OS and DFS than those of PD-L1 negative patients in both cohorts. Positive TC PD-L1 (I,J,K,L) and IC PD-L1 (M,N,O,P) did not show any significant prognostic value for OS or DFS in SCC patients. ADC, adenocarcinoma; TC, tumor cell; OS, overall survival; DFS, disease-free survival; SCC, squamous cell carcinoma; IC, immune cell.

clinical response (17-20). Therefore, we inferred that the biomarkers indicating $\mathrm{T}$ cell function were distinct between the two sub-types.

Adaptive and intrinsic immune resistance modalities are mechanisms for regulating PD-L1 expression by TCs. PD$\mathrm{L} 1$ up-regulation in response to IFN- $\gamma$ secreted by $\mathrm{CD} 8^{+} \mathrm{T}$ cells reflects adaptive resistance, which in turn represents a dynamic biomarker of active inflammation $(21,22)$.
Meanwhile, intrinsic resistance is observed in increased PDL1 expression secondary to constitutive oncogene activation (23-27). Staining of NSCLC specimens in this study showed that PD-L1 expression on ICs was significantly correlated with $\mathrm{CD}^{+} \mathrm{T}$ cell density in both subgroups, indicating an adaptive resistance. As for PD-L1 in TCs, a positive correlation with $\mathrm{CD} 8^{+} \mathrm{T}$ cells was observed in ADC, but not in SCC. Besides, GO analysis based on the 
A

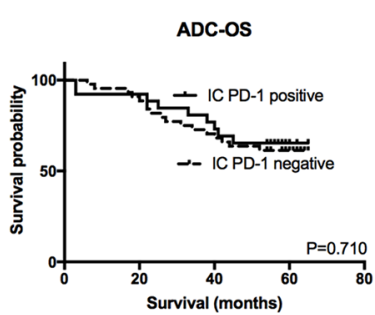

$\mathrm{E}$

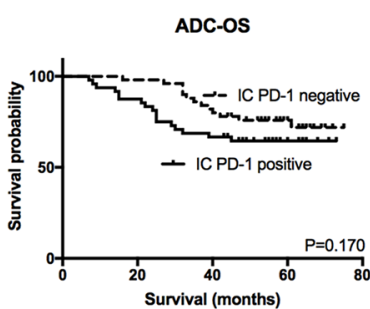

I



B

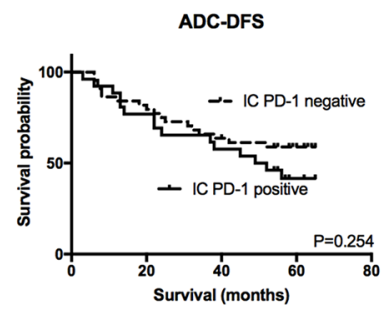

$\mathrm{F}$

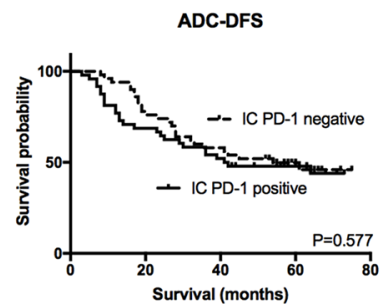

J

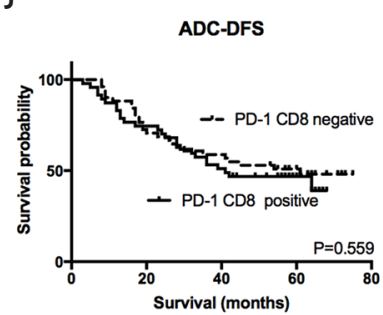

C

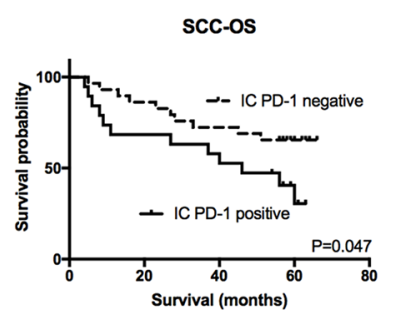

G

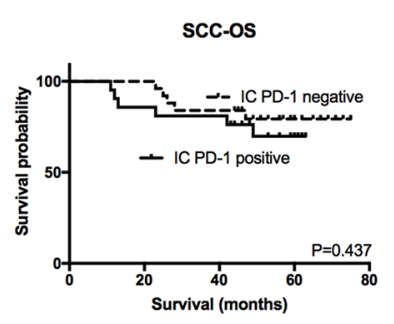

K

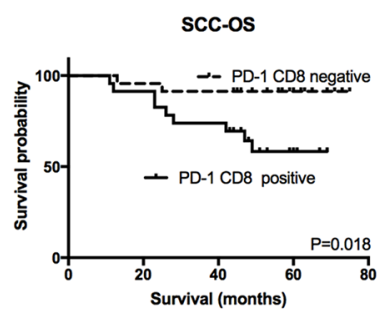

D

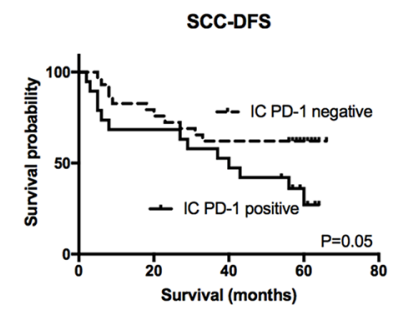

$\mathrm{H}$

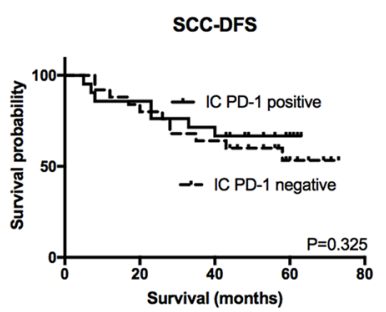

$\mathrm{L}$

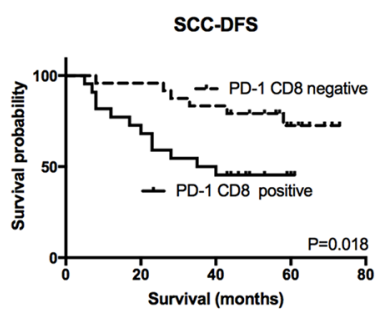

Figure 5 Kaplan-Meier survival analysis for PD-1 expression. PD-1 expression did not show a significant prognostic value for ADC patients in cohort $1(\mathrm{~A}, \mathrm{~B})$ or cohort 2 (E,F). PD-1+ TILs had a negative correlation with prognosis in SCC patients in cohort 1 (C,D). (G,H) In cohort 2, total PD-1 level did not show a significant prognostic value for SCC patients. (I,J) In cohort 2, the subgroup of CD8+PD-1+ did not show a significant prognostic value for ADC patients. $(\mathrm{K}, \mathrm{L})$ In cohort 2, SCC patients with positive CD8+PD-1+ expression exhibited significantly worse OS and DFS than patients with negative expression. SCC, squamous cell carcinoma; ADC, lung adenocarcinoma; TILs, tumor infiltrating lymphocytes; OS, overall survival; DFS, disease free survival.

TCGA database showed immune response with PD-L1 only in ADC, further supporting the hypothesis of a distinct regulatory mechanism of PD-L1 in TCs. This means that the PD-L1 expression in ADC TCs might occur due to the adaptive resistance or combined action of adaptive resistance and an intrinsic mechanism. Although PD-L1 was more frequently and more intensively expressed in SCC, it showed no up-regulation upon stimulation of CD8 ${ }^{+}$ $\mathrm{T}$ cells. Thus, intrinsic resistance is perhaps considered as the predominant regulatory mechanism in SCC. These findings, to some extent, support our speculation that $\mathrm{PD}$ $\mathrm{L} 1$ expression in $\mathrm{ADC}$ may represent the state of $\mathrm{CD} 8^{+} \mathrm{T}$ cells and thus serve as a prognostic marker.

TILs are another key factor in adaptive immunity. However, in cancer, sustained up-regulation of inhibitory receptors, on TILs has been found to lead to functional deficiency of TILs (28), and this dysfunctional state of $\mathrm{T}$ cells has been defined as T-cell exhaustion (18,29-31). PD-1 is the major inhibitory receptor that regulates T-cell exhaustion, and the associated clinical benefits obtained by antibodies of PD-1 or PD-L1 highlight the importance of this mechanism. Previous research has proven that the effect or function of PD- $1^{+}$TILs in NSCLC is impaired (18); however, $\mathrm{PD}-1^{+} \mathrm{CD} 8^{+} \mathrm{T}$ cells have been found to show a strong correlation with anti-PD1 therapy $(18,32)$. This shows that PD-1 expression can affect the function of $\mathrm{CD} 8^{+} \mathrm{T}$ cells. In our study, $\mathrm{CD} 8^{+} \mathrm{PD}-1^{+}$was considered as a predictive biomarker of shorter OS and DFS in SCC, indicating a state of T-cell dysfunction.

To date, no consensus regarding the association of 
PD-L1 and PD-1 with survival has been reached. The observations presented in our paper might reflect inherent differences in the immune environments of ADC and SCC. We also demonstrated a negative correlation of PD-L1 and PD-1 between different prognoses. Although there is evidence that TILs are associated with immune response, the prognostic predictive value of $\mathrm{CD} 8^{+} \mathrm{T}$ cells remain controversial (33-35). A possible reason for this is that the count of $\mathrm{CD}^{+} \mathrm{T}$ cells was insufficient to reflect the immune status, as T cells' function was more important. In ADC, the up-regulation of PD-L1 was subsequently associated with adaptive immune resistance and the induction of T-cell suppression through PD-L1 and PD-1 binding. The induction of PD-L1 is the key step during this process; thus, $\mathrm{PD}-\mathrm{L} 1$ could be used as a prognostic and predictive marker. However, PD-L1 was found to be up-regulated due to intrinsic immune resistance and pre-existence in SCC. Concurrently, PD-1 expression, which is especially expressed on TILs, reflected the status of the TME in triggering the reaction.

Some studies may have offered possible molecular evidence of involvement in suppressing immune responses in SCC patients in recent years. Leclerc et al. reported neuropilin-1 (Nrp-1) to define a subset of $\mathrm{CD}^{+} \mathrm{T}$ cells that can display PD- $1^{\text {hi }}$ status and negatively influence $\mathrm{CD} 8^{+} \mathrm{T}$ cell immunity (36). Another report has identified CD103 and its ligand $\mathrm{E}$-cadherin as important adhesion molecules that promote TIL anti-tumor functions in human lung tumors (37).

A limitation of this research was that it did not include data on therapy in post-operative recurrence cases, which have could influence the OS time of patients, especially with the development of novel agents for lung cancer in recent years. To some extent, DFS, which was unaffected by therapy for post-operative recurrence, was analyzed to address this problem. The clinical relevance of treatment factors with the PD-1/PD-L1 pathway and OS needs to be elucidated in future research. Another limitation is that these findings were established in a relatively smaller cohort, thus larger future studies are warranted for confirmation. Lastly, although we have uncovered the difference between NSCLC subtypes from the perspective of such a phenomenon, the specific molecular mechanism remains unclear and will focus on our future research.

In conclusion, the current findings give an insight into the distinct factors that indicate the $\mathrm{T}$ cell state between ADC and SCC. Different regulatory mechanisms and prognostic values of $\mathrm{PD}-\mathrm{L} 1$ have also been discovered. This work expanded our knowledge of the PD-L1/PD-1 pathway and provides a theoretical basis for optimizing current immunotherapy.

\section{Acknowledgments}

Funding: This work was supported by National Science and Technology Major Project of the Ministry of Science and Technology of China (2017ZX09304025); the National Natural Science Foundation of China (81602098, 81673025, and 31300743); Science and Technology Plan Project of Liaoning Province (2014225013, 2014226033, and 2016007010); Distinguished professor of Liaoning Province; The General Project of Liaoning Province Department of Education (LZ2014037).

\section{Footnote}

Reporting Checklist: The authors have completed the REMARK reporting checklist. Available at http://dx.doi. org/10.21037/atm-20-968

Data Sharing Statement: Available at http://dx.doi. org/10.21037/atm-20-968

Peer Review File: Available at http://dx.doi.org/10.21037/ atm-20-968

Conflicts of Interest: All authors have completed the ICMJE uniform disclosure form (available at http://dx.doi. org/10.21037/atm-20-968). The authors have no conflicts of interest to declare.

Ethical Statement: The authors are accountable for all aspects of the work in ensuring that questions related to the accuracy or integrity of any part of the work are appropriately investigated and resolved. The study was conducted in line with the Declaration of Helsinki (as revised in 2013) and approved by the Ethics Committee at the First Hospital of China Medical University (AF-SOP-07-1.1-01). All patients signed informed consent form.

Open Access Statement: This is an Open Access article distributed in accordance with the Creative Commons Attribution-NonCommercial-NoDerivs 4.0 International License (CC BY-NC-ND 4.0), which permits the noncommercial replication and distribution of the article with the strict proviso that no changes or edits are made and the 
original work is properly cited (including links to both the formal publication through the relevant DOI and the license). See: https://creativecommons.org/licenses/by-nc-nd/4.0/.

\section{References}

1. Brahmer J, Reckamp KL, Baas P, et al. Nivolumab versus Docetaxel in Advanced Squamous-Cell Non-Small-Cell Lung Cancer. N Engl J Med 2015;373:123-35.

2. Borghaei H, Paz-Ares L, Horn L, et al. Nivolumab versus Docetaxel in Advanced Nonsquamous Non-Small-Cell Lung Cancer. N Engl J Med 2015;373:1627-39.

3. Herbst RS, Baas P, Kim DW, et al. Pembrolizumab versus docetaxel for previously treated, PD-L1-positive, advanced non-small-cell lung cancer (KEYNOTE-010): a randomised controlled trial. Lancet 2016;387:1540-50.

4. Carbone DP, Reck M, Paz-Ares L, et al. First-Line Nivolumab in Stage IV or Recurrent Non-Small-Cell Lung Cancer. N Engl J Med 2017;376:2415-26.

5. Wu YL, Lu S, Cheng Y, et al. Nivolumab Versus Docetaxel in a Predominantly Chinese Patient Population With Previously Treated Advanced Non-Small Cell Lung Cancer: CheckMate 078 Randomized Phase III Clinical Trial. J Thorac Oncol 2019;14:867-75.

6. Topalian SL, Hodi FS, Brahmer JR, et al. Safety, activity, and immune correlates of anti-PD-1 antibody in cancer. N Engl J Med 2012;366:2443-54.

7. McLaughlin J, Han G, Schalper KA, et al. Quantitative Assessment of the Heterogeneity of PD-L1 Expression in Non-Small-Cell Lung Cancer. JAMA Oncol 2016;2:46-54.

8. Tang H, Wang Y, Chlewicki LK, et al. Facilitating T Cell Infiltration in Tumor Microenvironment Overcomes Resistance to PD-L1 Blockade. Cancer Cell 2016;29:285-96.

9. Fridman WH, Pages F, Sautes-Fridman C, et al. The immune contexture in human tumours: impact on clinical outcome. Nat Rev Cancer 2012;12:298-306.

10. Ilie $M$, Long-Mira E, Bence $C$, et al. Comparative study of the PD-L1 status between surgically resected specimens and matched biopsies of NSCLC patients reveal major discordances: a potential issue for anti-PD-L1 therapeutic strategies. Ann Oncol 2016;27:147-53.

11. Velcheti V, Schalper KA, Carvajal DE, et al. Programmed death ligand-1 expression in non-small cell lung cancer. Lab Invest 2014;94:107-16.

12. Tsao MS, Le Teuff G, Shepherd FA, et al. PD-L1 protein expression assessed by immunohistochemistry is neither prognostic nor predictive of benefit from adjuvant chemotherapy in resected non-small cell lung cancer. Ann Oncol 2017;28:882-9.

13. Mao Y, Li W, Chen K, et al. B7-H1 and B7-H3 are independent predictors of poor prognosis in patients with non-small cell lung cancer. Oncotarget 2015;6:3452-61.

14. Uruga H, Bozkurtlar E, Huynh TG, et al. Programmed Cell Death Ligand (PD-L1) Expression in Stage II and III Lung Adenocarcinomas and Nodal Metastases. J Thorac Oncol 2017;12:458-66.

15. Scheel AH, Ansen S, Schultheis AM, et al. PD-L1 expression in non-small cell lung cancer: Correlations with genetic alterations. Oncoimmunology 2016;5:e1131379.

16. Yang CY, Lin MW, Chang YL, et al. Programmed cell death-ligand 1 expression in surgically resected stage I pulmonary adenocarcinoma and its correlation with driver mutations and clinical outcomes. Eur J Cancer 2014;50:1361-9.

17. Azuma K, Ota K, Kawahara A, et al. Association of PDL1 overexpression with activating EGFR mutations in surgically resected nonsmall-cell lung cancer. Ann Oncol 2014;25:1935-40.

18. Lavin Y, Kobayashi S, Leader A, et al. Innate Immune Landscape in Early Lung Adenocarcinoma by Paired Single-Cell Analyses. Cell 2017;169:750-765.e17.

19. Thommen DS, Koelzer VH, Herzig P, et al. A transcriptionally and functionally distinct PD-1(+) CD8(+) T cell pool with predictive potential in nonsmall-cell lung cancer treated with PD-1 blockade. Nat Med 2018;24:994-1004.

20. Simoni Y, Becht E, Fehlings M, et al. Bystander CD8(+) $T$ cells are abundant and phenotypically distinct in human tumour infiltrates. Nature 2018;557:575-9.

21. Chevrier S, Levine JH, Zanotelli VRT, et al. An Immune Atlas of Clear Cell Renal Cell Carcinoma. Cell 2017;169:736-749.e18.

22. Spranger S, Spaapen RM, Zha Y, et al. Up-regulation of PD-L1, IDO, and T(regs) in the melanoma tumor microenvironment is driven by CD8(+) T cells. Sci Transl Med 2013;5:200ra116.

23. Abiko K, Matsumura N, Hamanishi J, et al. IFNgamma from lymphocytes induces PD-L1 expression and promotes progression of ovarian cancer. $\mathrm{Br} \mathrm{J}$ Cancer 2015;112:1501-9.

24. Cheng H, Liu P, Zhang F, et al. A genetic mouse model of invasive endometrial cancer driven by concurrent loss of Pten and Lkb1 is highly responsive to mTOR inhibition. Cancer Res 2014;74:15-23.

25. Atsaves V, Tsesmetzis N, Chioureas D, et al. PD-L1 is 
commonly expressed and transcriptionally regulated by STAT3 and MYC in ALK-negative anaplastic large-cell lymphoma. Leukemia 2017;31:1633-7.

26. Coelho MA, de Carne Trecesson S, Rana S, et al. Oncogenic RAS Signaling Promotes Tumor Immunoresistance by Stabilizing PD-L1 mRNA. Immunity 2017;47:1083-1099.e6.

27. Chen N, Fang W, Zhan J, et al. Upregulation of PDL1 by EGFR Activation Mediates the Immune Escape in EGFR-Driven NSCLC: Implication for Optional Immune Targeted Therapy for NSCLC Patients with EGFR Mutation. J Thorac Oncol 2015;10:910-23.

28. Dong ZY, Zhong WZ, Zhang XC, et al. Potential Predictive Value of TP53 and KRAS Mutation Status for Response to PD-1 Blockade Immunotherapy in Lung Adenocarcinoma. Clin Cancer Res 2017;23:3012-24.

29. Baitsch L, Baumgaertner P, Devevre E, et al. Exhaustion of tumor-specific CD8(+) T cells in metastases from melanoma patients. J Clin Invest 2011;121:2350-60.

30. Day CL, Kaufmann DE, Kiepiela P, et al. PD-1 expression on HIV-specific T cells is associated with T-cell exhaustion and disease progression. Nature 2006;443:350-4.

31. Thommen DS, Schreiner J, Muller P, et al. Progression of
Lung Cancer Is Associated with Increased Dysfunction of T Cells Defined by Coexpression of Multiple Inhibitory Receptors. Cancer Immunol Res 2015;3:1344-55.

32. Wherry EJ. T cell exhaustion. Nat Immunol 2011;12:492-9.

33. Daud AI, Loo K, Pauli ML, et al. Tumor immune profiling predicts response to anti-PD-1 therapy in human melanoma. J Clin Invest 2016;126:3447-52.

34. Thompson ED, Zahurak M, Murphy A, et al. Patterns of PD-L1 expression and CD8 $\mathrm{T}$ cell infiltration in gastric adenocarcinomas and associated immune stroma. Gut 2017;66:794-801.

35. Liu SY, Dong ZY, Wu SP, et al. Clinical relevance of PD$\mathrm{L} 1$ expression and CD8+ T cells infiltration in patients with EGFR-mutated and ALK-rearranged lung cancer. Lung Cancer 2018;125:86-92.

36. Leclerc M, Voilin E, Gros G, et al. Regulation of antitumour CD8 T-cell immunity and checkpoint blockade immunotherapy by Neuropilin-1. Nat Commun 2019,10:3345.

37. Boutet $M$, Gauthier L, Leclerc $M$, et al. TGF-b signaling intersects with CD103 integrin signaling to promote $\mathrm{T}$ lymphocyte accumulation and antitumor activity in the lung tumor microenvironment. Cancer Res 2016,76:1757-69.
Cite this article as: Wang S, Qu X, Li Z, Che X, Cao L, Yang X, Hu X, Xu L, Hou K, Fan Y, Wen T, Liu Y. Distinct prognostic values of programmed death-ligand 1 and programmed cell death protein 1 in lung adenocarcinoma and squamous cell carcinoma patients. Ann Transl Med 2021;9(5):397. doi: 10.21037/ atm-20-968 
A

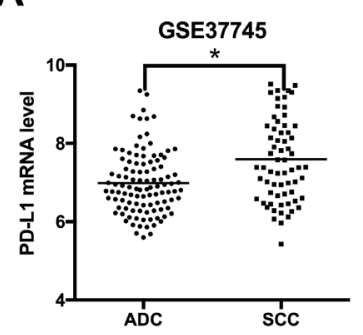

E

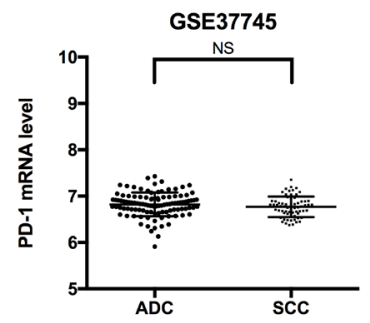

B

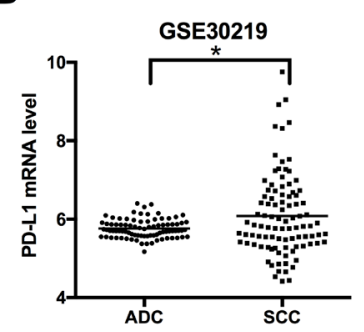

F

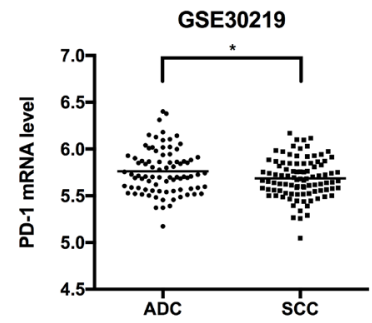

C

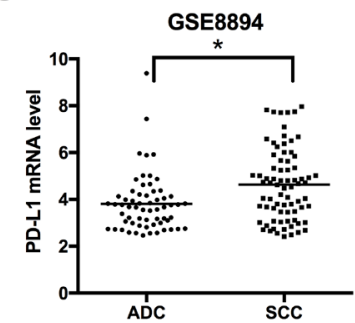

G

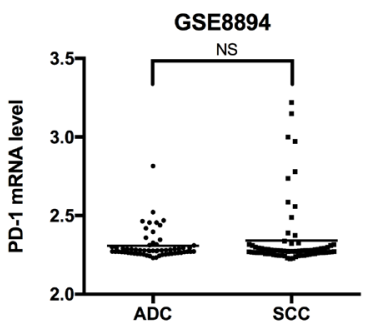

D

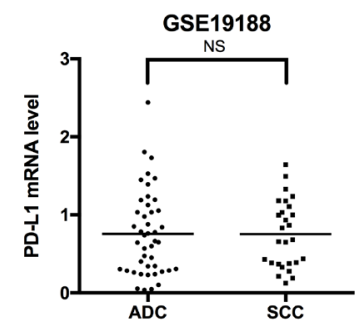

H



Figure S1 The mRNA level of PD-L1 and PD-1 based on the GEO database. (A,B,C,D) PD-L1 mRNA level of ADC and SCC in GEO database. (E,F,G,H) PD-1 mRNA level of ADC and SCC in GEO database. SCC, squamous cell carcinoma; ADC, lung adenocarcinoma. *, $\mathrm{P}<0.05$.

A

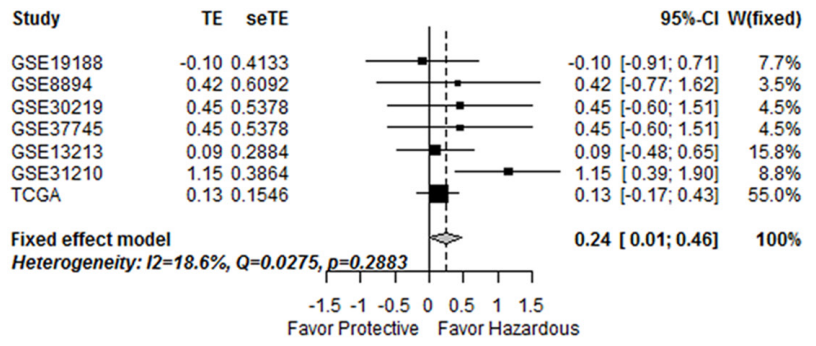

B

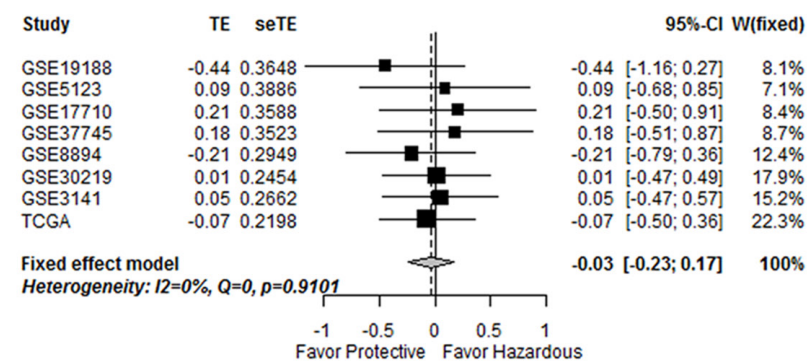

C

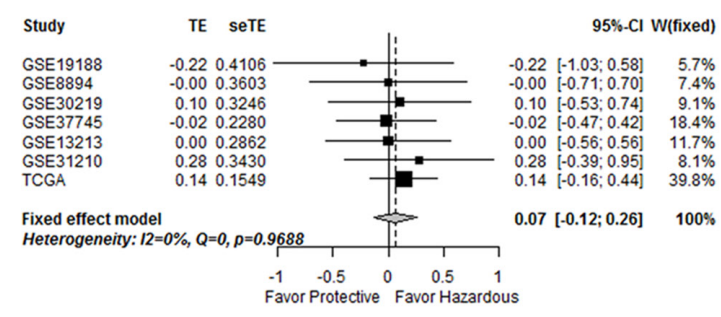

D

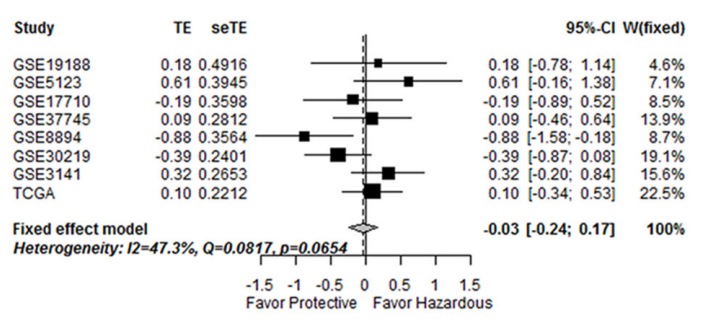

Figure S2 Meta-analysis of OS against PD-L1 and PD-1 levels. HR plot of OS against PD-L1 levels in ADC patients (A) and SCC patients (B). HR plot of OS against PD-1 levels in ADC patients (C) and SCC patients (D). OS, overall survival; HR, hazard ratio; SCC, squamous cell carcinoma; ADC, lung adenocarcinoma. 
Table S1 Baseline characteristics of two cohorts

\begin{tabular}{|c|c|c|c|c|c|c|c|c|}
\hline \multirow[b]{2}{*}{ Characteristics } & \multicolumn{4}{|c|}{ Cohort No.1 ( $\mathrm{N}=118) \%$} & \multicolumn{4}{|c|}{ Cohort No.2 (N=144) \% } \\
\hline & $\begin{array}{c}\text { Total }(\mathrm{N}=118), \\
\mathrm{N}(\%)\end{array}$ & $\begin{array}{c}\text { ADC }(N=70) \\
N(\%)\end{array}$ & $\begin{array}{c}\operatorname{SCC}(N=48) \\
N(\%)\end{array}$ & $P$ & $\begin{array}{c}\text { Total }(\mathrm{N}=144) \\
\mathrm{N}(\%)\end{array}$ & $\begin{array}{c}\text { ADC }(\mathrm{N}=98) \\
\mathrm{N}(\%)\end{array}$ & $\begin{array}{c}\operatorname{SCC}(N=64) \\
N(\%)\end{array}$ & $\mathrm{P}$ \\
\hline Age median (range) & $59(30-75)$ & $58(35-74)$ & $60(41-75)$ & 0.708 & $59(34-75)$ & $58(34-75)$ & $60(43-75)$ & 0.213 \\
\hline$<60$ & $60(50.8)$ & $37(61.7)$ & $23(38.3)$ & & $80(55.6)$ & $58(72.5)$ & $22(27.5)$ & \\
\hline$\geq 60$ & $58(49.2)$ & $33(59.3)$ & $25(40.7)$ & & $64(44.4)$ & $40(62.5)$ & $24(37.5)$ & \\
\hline Gender & & & & $<0.001$ & & & & $<0.001$ \\
\hline Male & $76(64.4)$ & $33(43.4)$ & $43(56.6)$ & & $82(56.9)$ & $41(50.0)$ & $41(50.0)$ & \\
\hline Female & $42(35.6)$ & $37(88.1)$ & $5(11.9)$ & & $62(43.1)$ & 57 (91.9) & $5(8.1)$ & \\
\hline Smoking status & & & & 0.001 & & & & $<0.001$ \\
\hline Never-smoker & $60(50.8)$ & $45(75.0)$ & $15(25.0)$ & & $79(54.9)$ & $70(88.6)$ & $9(11.4)$ & \\
\hline Ever-smoker & $58(49.2)$ & $25(43.1)$ & $33(56.9)$ & & $65(45.1)$ & $28(43.1)$ & 37 (56.9) & \\
\hline Tumor differentiation & & & & 0.008 & & & & 0.008 \\
\hline Well & $46(39.0)$ & $35(76.1)$ & $11(23.9)$ & & $41(28.5)$ & $33(80.5)$ & $8(19.5)$ & \\
\hline Moderate-poor & $72(61.0)$ & $36(50.0)$ & $36(50.0)$ & & $74(51.4)$ & $41(55.4)$ & $33(44.6)$ & \\
\hline Unknown & $0(0)$ & 0 & 0 & & $29(20.1)$ & $24(82.8)$ & $5(17.2)$ & \\
\hline pT stage & & & & 0.038 & & & & $<0.001$ \\
\hline $\mathrm{T} 1+2$ & $93(78.8)$ & $60(64.5)$ & $33(35.5)$ & & $41(28.5)$ & $37(90.2)$ & $4(9.8)$ & \\
\hline $\mathrm{T} 3+4$ & $25(21.2)$ & $10(40.0)$ & $15(60.0)$ & & $103(71.5)$ & $61(59.2)$ & $42(40.8)$ & \\
\hline Lymphatic invasion & & & & 0.708 & & & & 0.028 \\
\hline Negative & $60(50.8)$ & $37(61.7)$ & $23(38.3)$ & & 57 (39.6) & 45 (78.9) & $12(21.1)$ & \\
\hline Positive & $58(49.2)$ & 33 (56.9) & $25(43.1)$ & & $87(60.4)$ & $53(60.9)$ & $34(39.1)$ & \\
\hline pTNM stage & & & & 0.053 & & & & 0.072 \\
\hline I stage & $48(40.7)$ & $34(70.8)$ & $14(29.2)$ & & $47(32.6)$ & $38(80.9)$ & $9(19.1)$ & \\
\hline Il stage & $28(23.7)$ & $12(42.9)$ & $16(57.1)$ & & 47 (32.6) & $29(61.7)$ & $18(38.3)$ & \\
\hline III stage & $42(35.6)$ & $24(57.1)$ & $18(42.9)$ & & $50(34.7)$ & $31(62.0)$ & $19(38.0)$ & \\
\hline EGFR status & & & & $<0.001$ & & & & $<0.001$ \\
\hline Mutant & $51(43.2)$ & 47 (92.2) & $4(7.8)$ & & $64(44.4)$ & $56(87.5)$ & $8(12.5)$ & \\
\hline Wild type & $67(56.8)$ & $23(34.3)$ & $44(65.7)$ & & $47(55.6)$ & $42(52.5)$ & $38(47.5)$ & \\
\hline
\end{tabular}


Table S2 Spearman's correlation analysis of PD-L1 mRNA level of ADC by TCGA database

\begin{tabular}{|c|c|c|c|c|}
\hline Term & Count & $\%$ & $P$ value & Benjamini \\
\hline immune response & 12 & 20.0 & $2.8 E-5$ & 1.7E-2 \\
\hline regulation of cell cycle process & 5 & 8.3 & $7.6 \mathrm{E}-4$ & $2.0 \mathrm{E}-1$ \\
\hline regulation of cell cycle & 7 & 11.7 & $1.2 \mathrm{E}-3$ & $2.1 \mathrm{E}-1$ \\
\hline cell cycle & 10 & 16.7 & 1.7E-3 & $2.2 \mathrm{E}-1$ \\
\hline response to wounding & 8 & 13.3 & $2.8 \mathrm{E}-3$ & $2.9 \mathrm{E}-1$ \\
\hline negative regulation of $\mathrm{T}$ cell proliferation & 3 & 5.0 & 4.3E-3 & $3.5 \mathrm{E}-1$ \\
\hline negative regulation of leukocyte proliferation & 3 & 5.0 & $5.9 E-3$ & $4.0 \mathrm{E}-1$ \\
\hline negative regulation of mononuclear cell proliferation & 3 & 5.0 & $5.9 \mathrm{E}-3$ & 4.0E-1 \\
\hline negative regulation of lymphocyte proliferation & 3 & 5.0 & $5.9 E-3$ & $4.0 \mathrm{E}-1$ \\
\hline regulation of cell proliferation & 9 & 15.0 & $6.8 \mathrm{E}-3$ & 4.0E-1 \\
\hline
\end{tabular}

Table S3 Spearman's correlations between PD-L1 and CD8 ${ }^{+}$TILs of two cohorts

\begin{tabular}{|c|c|c|c|c|c|c|c|c|}
\hline \multirow{3}{*}{ PD-L1 expression } & \multicolumn{4}{|c|}{ Cohort No.1 } & \multicolumn{4}{|c|}{ Cohort No.2 } \\
\hline & \multicolumn{2}{|c|}{$\mathrm{CD8}^{+} \mathrm{TILs}$ in ADC } & \multicolumn{2}{|c|}{ CD8 ${ }^{+}$TILs in SCC } & \multicolumn{2}{|c|}{ CD8 ${ }^{+}$TILs in ADC } & \multicolumn{2}{|c|}{$\mathrm{CD}^{+} \mathrm{TILs}$ in SCC } \\
\hline & Spearman's r & $P$ value & Spearman's r & $\mathrm{P}$ value & Spearman's $r$ & $P$ value & Spearman's r & $\mathrm{P}$ value \\
\hline IC & 0.379 & 0.001 & 0.369 & 0.01 & 0.483 & $<0.001$ & 0.401 & 0.006 \\
\hline TC & 0.373 & 0.001 & 0.192 & 0.192 & 0.469 & $<0.001$ & 0.035 & 0.818 \\
\hline
\end{tabular}

Table S4 Characteristics of studies in meta-analysis for the overall survival in NSCLC

\begin{tabular}{|c|c|c|c|c|c|c|}
\hline \multirow{2}{*}{ Study name } & \multirow{2}{*}{ Type } & \multirow{2}{*}{$\mathrm{N}$} & \multicolumn{2}{|c|}{ PD-L1 } & \multicolumn{2}{|c|}{ PD-1 } \\
\hline & & & $\mathrm{HR}$ & $95 \% \mathrm{Cl}$ & $\mathrm{HR}$ & $95 \% \mathrm{Cl}$ \\
\hline GSE8894 & ADE & 62 & 1.528 & $0.745-3.133$ & 0.997 & $0.492-2.02$ \\
\hline GSE19188 & ADE & 45 & 0.906 & $0.405-2.025$ & 0.801 & $0.358-1.79$ \\
\hline GSE30219 & ADE & 84 & 1.57 & $0.837-2.945$ & 1.109 & $0.587-2.095$ \\
\hline GSE31210 & ADE & 226 & 3.15 & $1.48-6.73$ & 1.32 & $0.67-2.57$ \\
\hline GSE13213 & ADE & 117 & 1.09 & $0.62-1.92$ & 1.0 & $0.57-1.75$ \\
\hline TCGA & ADE & 475 & 1.14 & $0.84-1.54$ & 1.15 & $0.85-1.56$ \\
\hline GSE5123 & SCC & 51 & 1.09 & $0.51-2.34$ & 1.84 & 0.85-3.99 \\
\hline GSE17710 & SCC & 56 & 1.23 & $0.61-2.49$ & 0.83 & $0.41-1.68$ \\
\hline TCGA & SCC & 175 & 0.93 & $0.6-1.42$ & 1.1 & $0.71-1.69$ \\
\hline GSE8894 & SCC & 76 & 0.808 & $0.415-1.571$ & 0.414 & $0.206-0.833$ \\
\hline GSE19188 & SCC & 27 & 0.642 & $0.246-1.676$ & 1.198 & $0.457-3.139$ \\
\hline GSE30219 & SCC & 96 & 1.014 & $0.641-1.603$ & 0.674 & 0.421-1.079 \\
\hline GSE37745 & SCC & 66 & 1.2 & $0.694-2.075$ & 1.095 & $0.631-1.9$ \\
\hline
\end{tabular}


Table S5 Univariate and multivariate survival analysis in Cohort No. 2

\begin{tabular}{|c|c|c|c|c|c|c|}
\hline \multirow{2}{*}{ Variables } & \multicolumn{3}{|c|}{ Univariate analysis } & \multicolumn{3}{|c|}{ Multivariate analysis } \\
\hline & $\mathrm{HR}$ & $95 \% \mathrm{Cl}$ & $\mathrm{P}$ & $\mathrm{HR}$ & $95 \% \mathrm{Cl}$ & $\mathrm{P}$ \\
\hline \multicolumn{7}{|l|}{ ADC } \\
\hline Age & 0.947 & $0.438-2.048$ & 0.89 & & & \\
\hline Gender & 0.985 & $0.445-2.131$ & 0.969 & & & \\
\hline Smoking status & 0.782 & $0.34-1.799$ & 0.536 & & & \\
\hline Differentiation & 3.285 & $1.379-7.827$ & $0.007^{\star \star}$ & & & \\
\hline TNM stage & 2.657 & $1.634-4.32$ & $0.000^{\star * \star}$ & 2.507 & $1.529-4.111$ & $0.000^{\star * *}$ \\
\hline EGFR status & 0.871 & $0.388-1.954$ & 0.737 & & & \\
\hline PD-L1 & 3.291 & $1.381-7.840$ & $0.007^{\star \star}$ & 2.658 & $1.110-6.364$ & $0.028^{\star}$ \\
\hline CD8 ${ }^{+} \mathrm{PD}-1$ & 0.859 & $0.383-1.926$ & 0.712 & & & \\
\hline \multicolumn{7}{|l|}{ SCC } \\
\hline Age & 1.481 & $0.632-3.473$ & 0.366 & & & \\
\hline Gender & 1.274 & $0.298-5.457$ & 0.744 & & & \\
\hline Smoking status & 1.29 & 0.505-3.299 & 0.594 & & & \\
\hline Differentiation & 0.935 & $0.344-2.541$ & 0.895 & & & \\
\hline TNM stage & 2.512 & $1.355-4.657$ & $0.003^{\star *}$ & 2.482 & $1.349-4.567$ & $0.003^{\star *}$ \\
\hline EGFR status & 0.042 & $0-15.277$ & 0.291 & & & \\
\hline PD-L1 & 0.832 & $0.246-2.819$ & 0.768 & & & \\
\hline $\mathrm{CD}^{+} \mathrm{PD}-1$ & 2.285 & $0.985-5.299$ & 0.054 & 2.304 & $0.988-5.371$ & 0.053 \\
\hline
\end{tabular}

${ }^{\star} \mathrm{P}<0.05,{ }^{\star \star} \mathrm{P}<0.01,{ }^{* \star *} \mathrm{P}<0.001$. 